\title{
BMJ Open Developing a complex intervention to improve prescribing safety in primary care: mixed methods feasibility and optimisation pilot study
}

\author{
Aileen M Grant, ${ }^{1}$ Bruce Guthrie, ${ }^{1}$ Tobias Dreischulte ${ }^{2}$
}

To cite: Grant AM, Guthrie B, Dreischulte T. Developing a complex intervention to improve prescribing safety in primary care: mixed methods feasibility and optimisation pilot study. BMJ Open 2014;4:e004153.

doi:10.1136/bmjopen-2013004153

- Prepublication history for this paper is available online. To view these files please visit the journal online (http://dx.doi.org/10.1136/ bmjopen-2013-004153).

Received 30 September 2013 Revised 29 November 2013 Accepted 19 December 2013

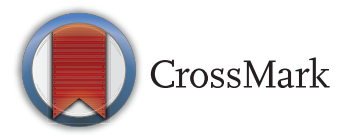

For numbered affiliations see end of article.

Correspondence to Aileen M Grant; a.m.grant@dundee.ac.uk

\section{ABSTRACT}

Objectives: (A) To measure the extent to which different candidate outcome measures identified highrisk prescribing that is potentially changeable by the data-driven quality improvement in primary care (DQIP) intervention.(B) To explore the value of reviewing identified high-risk prescribing to clinicians.(C) To optimise the components of the DQIP intervention.

Design: Mixed method study.

Setting: General practices in two Scottish Health boards.

Participants: 4 purposively sampled general practices of varying size and socioeconomic deprivation.

Outcome measures: Prescribing measures targeting (1) high-risk use of the non-steroidal antiinflammatory drugs (NSAIDs) and antiplatelets; (2) 'Asthma control' and (3) 'Antithrombotics in atrial fibrillation (AF)'.

Intervention: The prescribing measures were used to identify patients for review by general practices. The ability of the measures to identify potentially changeable high-risk prescribing was measured as the proportion of patients reviewed where practices identified a need for action. Field notes were recorded from meetings between researchers and staff and key staff participated in semistructured interviews exploring their experience of the piloted intervention processes.

Results: Practices identified a need for action in $68 \%$, $25 \%$ and $18 \%$ of patients reviewed for prescribing measures (1), (2) and (3), respectively. General practitioners valued being prompted to review patients, and perceived that (1) 'NSAID and antiplatelet' and (2) 'antithrombotics in AF' were the most important to act on. Barriers to initial and ongoing engagement and to sustaining improvements in prescribing were identified. Conclusions: 'NSAIDs and antiplatelets' measures were selected as the most suitable outcome measures for the DQIP trial, based on evidence of this prescribing being more easily changeable. In response to the barriers identified, the intervention was designed to include a financial incentive, additional ongoing feedback on progress and reprompting review of patients, whose high-risk prescribing was restarted after a decision to stop.

Trial registration number: Clinicaltrials.gov NCT01425502.

\section{Strengths and limitations of this study}

- The key strength of this study was the use of quantitative and qualitative methods to give a greater understanding of how changeable the identified high-risk prescribing was, what the barriers to changing prescribing were and how general practitioners (GPs) valued this work.

- The findings of this pilot study enabled informed choice of outcome measures and optimisation of the intervention to be tested in the DQIP trial.

- The limitation of this study is that changeabilityof potential outcome measures was tested by measuring GPs intention to change prescribing or conduct further investigation ('action'), rather than quantifying actual changes in prescribing and their clinical implications (although this is being evaluated in an ongoing clusterrandomised controlled trial).

\section{BACKGROUND}

The safety of medication use in primary care is a major concern for healthcare systems internationally. $^{1-4}$ An estimated $3-4 \%$ of unplanned hospital admissions are due to preventable adverse drug events and approximately one-third of these have been attributed to prescribing of drugs to people with risk factors for adverse drug effects and underprescribing of prophylactic treatments (high-risk prescribing).

In the UK, medications may be initiated in primary and secondary care, but general practitioners (GPs) prescribe almost all drugs in the community and have responsibility for reviewing all medications. Previous research has shown that high-risk prescribing in primary care is common and its prevalence varies substantially between practices (after adjusting for case-mix), which indicates scope for improvement. ${ }^{5-8}$ Given the current UK policy focus on improving patient safety, there is a need to develop and test interventions to reduce high-risk prescribing. ${ }^{10}$ 
In the UK, the virtually ubiquitous use of electronic medical records (EMRs) in primary care offers opportunities to support quality and safety improvement initiatives. For example, the PINCER (Pharmacist-led Information Technology Intervention for Medication Errors) trial has demonstrated the effectiveness of an intervention, where pharmacists identified patients with high-risk prescribing using data extracted from EMRs, reviewed their records and recommended changes. ${ }^{11}$ Similarly, the 'Data-driven quality improvement in primary care' (DQIP) research programme aims to identify patients with high-risk prescribing from EMRs, but in contrast to PINCER, practices are provided with continuous feedback using a web-based informatics tool and financial incentives to motivate practice staff to review patients identified. ${ }^{12}$

The Medical Research Council (MRC) framework recommends that complex interventions be modelled before evaluation in a randomised controlled trial in order to optimise the intervention design and its evaluation by defining outcomes and ensuring feasibility. ${ }^{13} 14$ In terms of intervention design, the broad shape of the DQIP intervention was defined by the intention that there should be evidence for the effectiveness of its components, that it should be built on existing National Health Service (NHS) information technology and be implementable as an 'enhanced service' (a UK National Health Service mechanism for commissioning general practice care). The intention was therefore to combine an educational intervention, ${ }^{15} 16$ audit and feedback, ${ }^{17}$ and a financial incentive to review. As a result, a priority was to pilot and optimise these elements in a small number of practices. For evaluating the impact of the intervention, a set of potential prescribing outcome measures had previously been validated using consensus methods ${ }^{5}$ but an outstanding question was which of these measures could plausibly be improved by this intervention and therefore used as trial outcome measures.

The specific objectives of this study were to optimise the DQIP intervention and trial evaluation by: (1) identifying which potential outcome measures best identified patients with high-risk prescribing that could potentially be changed; (2) establishing which measures were most valued by practices in terms of improving quality and safety; (3) exploring how best to design and deliver the educational, informatics and financial components of the DQIP intervention to maximise the practice engagement.

\section{METHODS}

\section{Settings}

We purposively sampled and recruited four general practices, two from each NHS Scotland Health Board where the intervention was to be trialled, aiming to include larger and smaller practices serving populations that varied in socioeconomic deprivation.

\section{Data collection}

Data collection was between March 2010 and August 2011.

\section{Quantitative data}

In each practice, thematically related prescribing measures ('prescribing topics') that had been identified as priorities for quality and safety improvement ${ }^{5}$ were implemented in EMRs to identify patients with potentially suboptimal prescribing for review. These prescribing topics were: (1) high-risk use of non-steroidal anti-inflammatory drugs (NSAIDs) and antiplatelets in patients with gastrointestinal, renal or cardiac risk factors ('NSAIDs and antiplatelets'); (2) underuse of inhaled corticosteroids and high-risk use of $\beta$-blockers in asthma ('asthma control') and (3) overuse and underuse of antithrombotic drugs in atrial fibrillation (AF) ('antithrombotics in AF').

Practices received a feedback report for each topic, which summarised the total numbers of patients identified by each measure of high-risk prescribing, listed the patients affected and provided supporting educational material (rationale, current evidence and prescribing guidance). ${ }^{18}$ Practices were asked to conduct a record review of all identified patients with face-to-face review if necessary, and to document all decision-making on a structured template (tick boxes for a decision to 'change prescribing', conduct 'further investigation' or 'no action' and free text space to specify the rationale for 'no action'). Our expectation was that clinicians would judge some high-risk prescribing to be appropriate but would identify other patients in whom the prescribing should be stopped. An important aim of the pilot was to estimate how appropriateness and stopping varied across topics, to allow the trial to target prescribing that was more likely to be inappropriate and changeable.

\section{Qualitative data}

An initial meeting to explain the study and describe the topics was held in each practice. Practices then worked on one topic at a time, with further meetings held 68 weeks after practices had received and acted on the feedback report. The meetings were facilitated by the pharmacist (TD), and observed by AMG who took ethnographical field notes of $18 \mathrm{~h}$ of meetings. The whole practice was invited but the meetings were generally attended by the GP(s) most involved and the practice manager and lasted between 30 and $60 \mathrm{~min}$. At these meetings, practices were asked to describe the practice processes to conduct the review work, to report on the complexities of reviewing or changing prescribing and to expand on reasons for 'no action'.

The GPs most involved in the review work and practice managers were invited for individual semistructured interviews in order to explore their perceptions of the value of each prescribing topic and the specific components of the intervention (education, informatics and financial), their experiences of adopting and implementing the intervention in routine practice and to changing prescribing. Eleven interviews were conducted with eight GPs (one GP was interviewed twice) and two practice managers. These interviews were held in the 
practices, lasted approximately $1 \mathrm{~h}$, were audiorecorded and transcribed verbatim.

\section{Data analysis}

Quantitative analysis (research question $(R Q)$ 1: performance of prescribing measures)

The ability of each measure to identify potentially changeable high-risk prescribing was measured as the proportion of patients reviewed whose prescribing was judged to require action ('change prescribing' or 'further investigation'). Reasons why the measures failed to identify potentially changeable high-risk prescribing in patients were classified into three categories: 'clinical' (prescribing changes were deemed inappropriate or unnecessary given the clinical circumstances), 'technical' (the measure misidentified patients when implemented in live clinical data) and 'other'.

\section{Qualitative analysis (RQ2 perceived value of each prescribing topic and RQ3 optimising intervention components)}

Interview transcripts and field notes were merged and analysed by emerging themes to identify a coding frame. Data were imported into Nvivo- 8 and the coding frame was systematically applied. Subsequent analysis was by the framework technique. ${ }^{19}$ Thematic charting facilitated comparing the data by theme, practice and prescribing topic. The data were explored for negative cases.

\section{RESULTS}

Practice list-sizes ranged from 3200 to over 10 000, with the percentage of patients living in the most deprived quintile of postcodes ranging from $4 \%$ to $46 \%$. All four practices completed the 'NSAID and antiplatelet' and 'asthma control' topics, but only three completed the 'antithrombotics in AF' topic.

\section{Ability of measures to identify patients with potentially changeable high-risk prescribing}

Table 1 shows that for the 'NSAID and antiplatelet' topic, practices recorded a need for action in $68 \%$ of patients reviewed (change prescribing 35\%; further investigation $33 \%$ ) compared with only $25 \%$ of patients reviewed for the 'asthma control' topic (change prescribing $7 \%$; further investigation $18 \%$ ) and $18 \%$ of those reviewed for 'antithrombotics in AF' (change prescribing $1 \%$; further investigation $17 \%$ ).

Table 2 shows the rationales for no action reported by GPs on templates for each patient reviewed. Clinical reasons were most commonly reported for the "NSAIDs and antiplatelets' topic (67\%), but less so for the 'antithrombotics in $\mathrm{AF}$ ' $(36 \%)$ and much less for the 'asthma control' (4\%) topic. The reasons provided reflected that high-risk prescribing was a trade-off between effectiveness and safety. For 'NSAIDs and antiplatelets', the main reported reason for not changing prescribing was that NSAID use was only 'short term'. For 'antithrombotics

Table 1 Review decisions made by topic

\begin{tabular}{|c|c|c|c|}
\hline \multirow[b]{2}{*}{ Topic/individual measures implemented (number of reviews) } & \multicolumn{3}{|c|}{$\begin{array}{l}\text { Number of times the following decisions were made } \\
\text { at point of review }\end{array}$} \\
\hline & $\begin{array}{l}\text { Change } \\
\text { medication }\end{array}$ & $\begin{array}{l}\text { Further } \\
\text { investigation }\end{array}$ & No action \\
\hline 1 NSAIDS and antiplatelets $(n=290)$ & $101(35 \%)$ & 9/ (3) & $92(3$ \\
\hline 1.1 High-risk use in patients with GI risk factors $(n=120)^{\star}, \dagger$ & 54 & 21 & \\
\hline $\begin{array}{l}\text { 1.2 High-risk use of NSAIDs in patients with renal risk factors } \\
(n=161) \ddagger\end{array}$ & $44(27 \%)$ & $72(45 \%)$ & $45(28 \%)$ \\
\hline ligh-risk use of NSAIDs in heart failure $(n=9)$ & $3(33$ & $4(4$ & $2(2$ \\
\hline Asthma $(n=$ & 10 & 26 & 112 \\
\hline 1 Underuse of inhaled corticosteroids ( & & 23 & 100 \\
\hline of $\beta$-blockers $(n=18) \emptyset$ & \%) & 3( & 12 \\
\hline rillation $(n=201)$ & ) & $34(1$ & 164 \\
\hline 1 Underuse/low intensity of thromboembolic prophylaxis $(n=178)$ & & 34( & 143 \\
\hline 3.2 High-risk use of oral anticoagulants $(n=23)$ & $2(9 \%)$ & $0(0 \%)$ & $21(91 \%)$ \\
\hline \multicolumn{4}{|c|}{$\begin{array}{l}\text { The data reported on topics } 1 \text { (NSAID and antiplatelet) and } 2 \text { (asthma) measures are from all four practices and the topic } 3 \text { (atrial fibrillation) } \\
\text { data are from three of the pilot practices. } \\
\text { *NSAID prescription (in previous } 12 \text { weeks) without GI protection to people with at least one of the following risk factors: (i) history of peptic } \\
\text { ulcer, (ii) aged } \geq 75 \text {, (iii) aged } \geq 65 \text { and on aspirin, (iv) aged } \geq 65 \text { and on warfarin. } \\
\text { †Aspirin prescription (in previous } 12 \text { weeks) without GI protection to people with at least one of the following risk factors: (i) history of peptic } \\
\text { ulcer, (ii) aged } \geq 65 \text { and on clopidogrel, (iii) aged } \geq 65 \text { and on warfarin. } \\
\text { †NSAID prescription to people with at least one of the following risk factors: (i) CKD stages } 3-5 \text {, (ii) on ACEI/ARB, (iii) on diuretic, (iv) on } \\
\text { combination of ACEl/ARB and diuretic. } \\
\text { §No prescription of inhaled corticosteroid (in previous } 12 \text { weeks) in patient with asthma and at least one of the following risk factors: (i) } \\
\text { prescription for three or more SABA inhalers in previous } 12 \text { weeks, (ii) prescription of LABAs, leukotriene receptor antagonist, theophylline or } \\
\text { oral prednisolone in previous } 12 \text { weeks. } \\
\text { IPrescription of any } \beta \text {-blocker if 'active asthma' (prescription of a SABA inhaler in previous } 48 \text { weeks) or prescription of a non-cardioselective } \\
\beta \text {-blocker if 'previous asthma' (no prescription of a SABA inhaler in the previous } 48 \text { weeks). } \\
\text { ACEI/ARB, ACE inhibitors/angiotensin receptor blocker; CKD, chronic kidney disease; Gl, gastrointestinal; LABAs, long-acting } \beta 2 \text {-agonists; } \\
\text { NSAIDs, non-steroidal anti-inflammatory drugs; SABA, short acting } \beta \text { agonists. }\end{array}$} \\
\hline
\end{tabular}


in AF', clinical reasons reported were mainly 'unfitness for warfarin' (examples reported in interview included fragility and dementia, heavy alcohol use and previous gastrointestinal bleeding), but also included 'paroxysmal AF' (reflecting a misconception that stroke risk is lower than for patients with chronic $\mathrm{AF}$ ).$^{20}$

'Technical reasons' accounted for one-third of rationales for no action for the 'NSAID and antiplatelet' topic, and for $47 \%$ 'asthma control' and $48 \%$ of the 'antithrombotics in AF' topics. For all three topics, technical reasons related to patients no longer being on practice registers and to situations where identified high- risk prescribing was no longer present at the point of review ('time window of assessment'). For example, for the 'antithrombotics in AF' topic, all practices highlighted in interviews that anticoagulant prescribing intervals often exceeded the 12-week timeframe used by the measures, causing patients to be incorrectly identified as lacking antithrombotic prophylaxis.

Inaccurate disease registers were reported as reasons why 'antithrombotics in AF' and 'asthma control' measures misidentified prescribing as high risk. One practice reported in interview that many patients on their asthma disease register had chronic obstructive pulmonary

Table 2 Reasons stated by clinicians as to why 'no action' was required for patients identified with drug therapy risk(s) by the DQIP measures

\begin{tabular}{|c|c|c|c|}
\hline \multirow[b]{2}{*}{$\begin{array}{l}\text { Topic (number of } \\
\text { reviews) }\end{array}$} & \multicolumn{3}{|c|}{ Number of reviews where stated reason for 'no action' was* } \\
\hline & $\begin{array}{l}\text { 'Technical' (count, \%) specific } \\
\text { reasons (count) }\end{array}$ & $\begin{array}{l}\text { 'Clinical' specific reasons } \\
\text { (count) }\end{array}$ & $\begin{array}{l}\text { 'Other' specific reasons } \\
\text { (count) }\end{array}$ \\
\hline $\begin{array}{l}\text { 1. NSAIDS and } \\
\text { antiplatelets }(n=92)\end{array}$ & $30(33 \%)$ & $62(67 \%)$ & 0 \\
\hline \multirow{2}{*}{$\begin{array}{l}\text { 1.1 High-risk use in } \\
\text { patients with Gl risk } \\
\text { factors }(n=45)\end{array}$} & $10(22 \%)$ & $35(78 \%)$ & \multirow[t]{2}{*}{0} \\
\hline & $\begin{array}{l}\text { Patient no longer on practice } \\
\text { register (5); time window of } \\
\text { assessment }(3 \dagger) \text {; disease coding } \\
\text { error ( } 2)\end{array}$ & $\begin{array}{l}\text { Short-term use ( } 21) \text {; risk } \\
\text { adequately mitigated by low-dose } \\
\text { misoprostol (5); high-risk drug } \\
\text { 'well tolerated' (9); no effective } \\
\text { alternative (5) }\end{array}$ & \\
\hline 1.2 High-risk use of & $20(44 \%)$ & $20(44 \%)$ & $5(11 \%)$ \\
\hline $\begin{array}{l}\text { NSAIDs in patients with } \\
\text { renal risk factors }(n=45)\end{array}$ & $\begin{array}{l}\text { Time window of assessment } \\
(15 \dagger) \text {; patient no longer on } \\
\text { practice register (5) }\end{array}$ & $\begin{array}{l}\text { Short-term use (19); no effective } \\
\text { alternative (1) }\end{array}$ & Unspecified (5 $\ddagger)$ \\
\hline \multirow{2}{*}{$\begin{array}{l}\text { 1.3 High-risk use of } \\
\text { NSAIDs in heart failure } \\
(n=2)\end{array}$} & \multirow[t]{2}{*}{0} & $2(100 \%)$ & \multirow[t]{2}{*}{0} \\
\hline & & Short-term use (2) & \\
\hline 2. Asthma $(n=112)$ & $53(47 \%)$ & $5(4 \%)$ & $54(48 \%)$ \\
\hline \multirow{2}{*}{$\begin{array}{l}\text { 2.1 Underuse of inhaled } \\
\text { corticosteroids }(n=100)\end{array}$} & $46(46 \%)$ & \multirow[t]{2}{*}{0} & $54(54 \%)$ \\
\hline & $\begin{array}{l}\text { Time window of assessment } \\
(21 \dagger) \text {; proxies for moderate/ } \\
\text { severe asthma failed (13§); } \\
\text { disease coding error (10); patient } \\
\text { no longer on practice register (2) }\end{array}$ & & $\begin{array}{l}\text { Needs review but does not } \\
\text { attend clinic (29); recently } \\
\text { reviewed for QOF (22); } \\
\text { patient choice (3) }\end{array}$ \\
\hline \multirow{5}{*}{$\begin{array}{l}2.2 \text { High-risk use of } \\
\beta \text {-blockers }(n=12) \\
3 \text { AF }(n=166) \\
\text { 3.1 Underuse/low } \\
\text { intensity of } \\
\text { thromboembolic } \\
\text { prophylaxis }(n=143)\end{array}$} & $7(58 \%)$ & $5(42 \%)$ & \multirow[t]{2}{*}{0} \\
\hline & Disease coding error (7) & $\beta$-blocker 'well tolerated' (5) & \\
\hline & $80(48 \%)$ & $59(36 \%)$ & $27(16 \%)$ \\
\hline & $78(55 \%)$ & $42(29 \%)$ & $23(16 \%)$ \\
\hline & $\begin{array}{l}\text { Disease coding error }(31) \text {; time } \\
\text { window of assessment }(29 \dagger) \text {; } \\
\text { patient no longer on practice } \\
\text { register (18) }\end{array}$ & $\begin{array}{l}\text { Not 'fit' for warfarin (30); } \\
\text { paroxysmal AF (7); satisfactory } \\
\text { rate control (5) }\end{array}$ & $\begin{array}{l}\text { Patient choice (16); } \\
\text { secondary care decision } \\
\text { (3); unspecified (4) }\end{array}$ \\
\hline \multirow{2}{*}{$\begin{array}{l}\text { 3.2 High-risk use of oral } \\
\text { anticoagulants }(n=21)\end{array}$} & $2(10 \%)$ & 17 (81\%) & $2(10 \%)$ \\
\hline & Disease coding error (2) & $\begin{array}{l}\mathrm{CHADS}_{2} \text { score judged to } \\
\text { underestimate risk (17) }\end{array}$ & $\begin{array}{l}\text { Secondary care decision } \\
\text { (2) }\end{array}$ \\
\hline \multicolumn{4}{|c|}{$\begin{array}{l}\text { 'The number of specific reasons may exceed the number of reviews when more than one reason was provided per review. } \\
\text { †Refers to situations where a drug that was identified by the searches as 'high-risk' was stopped or a drug identified as 'beneficial' was } \\
\text { prescribed between the search date and the review date. } \\
\text { †The reasons provided referred to coexisting gastrointestinal risk factors. } \\
\text { §The proxies for moderate-to-severe asthma ( }>3 \text { prescriptions of short-acting } \beta \text { agonists issued over the past } 12 \text { weeks; prescription of step } 3 \\
\text { drugs) failed in these cases, because patients had mild asthma but were stock-piling inhalers (eg, getting them to have available in multiple } \\
\text { locations) or using step } 3 \text { drugs for indications other than asthma. } \\
\text { AF, atrial fibrillation; CHADS2, Additive stroke risk score (Cardiac failure (1), Hypertension (1), Age } \geq 75 \text { (1), Diabetes (1), Stroke (2)); DQIP, } \\
\text { data-driven quality improvement in primary care; Gl, gastrointestinal; NSAIDs, non-steroidal anti-inflammatory drugs; QOF, quality and } \\
\text { outcomes framework. }\end{array}$} \\
\hline
\end{tabular}


disease and therefore did not have a clear indication for treatment with inhaled corticosteroids. The deprived practices reported that high numbers of short-acting $\beta$-agonist prescriptions did not necessarily identify patients with uncontrolled asthma, because patients stockpiled inhalers in multiple locations (eg, home, school or work).

'Other' reasons were not commonly identified for 'NSAIDs and antiplatelets', but accounted for $16 \%$ of 'antithrombotics in AF' and for $48 \%$ of 'asthma control' reviews where no action was taken. For the latter, GPs reported that patients had recently received an annual quality and outcomes framework (QOF) review, usually from a nurse, and they therefore assumed them to be on optimised asthma treatment. GPs generally felt that changes in prescribing for asthma usually required face-to-face review but patients often did not respond to invitations for review.

\section{Perceived value of each prescribing topic as a target for the DQIP intervention}

GPs perceived the pilot intervention-raised awareness of targeted high-risk prescribing, improved prescribing practices and the recording of decision-making rationales, but they did not value each topic equally.

improving prescribing practice, improving our record keeping, improving our knowledge base and if people are on unsafe meds getting them off them and if there are on them carefully considering why and it is not accidental. (GP interview 1)

All GPs interviewed highly valued the process of reviewing patients identified as receiving high-risk NSAID or antiplatelet prescriptions.

\begin{abstract}
The topic is, I would go so far as to say, essential. I don't even think you can say it's urgent. It's essential that practices are doing this. They could be killing patients totally unnecessarily and it's not as if it's difficult, because in a lot of circumstances, the vast majority of them are nonsteroidals in elderly people. (GP interview 7)
\end{abstract}

The GPs interviewed perceived that NSAIDs are sometimes initiated with the intention the prescription was a one-off or without full consideration of all risk factors.

I've always thought I've been quite cautious with NSAIDs but then again possibly some of these patients were mine. You know they have been started on NSAID despite them being on ACE inhibitor and a diuretic and you think oh god, that's incredibly embarrassing. (GP interview 6).

Where risk factors were missed or NSAIDs were prescribed for longer than intended, GPs valued a prompt to review. In the interviews, GPs reported changes to the NSAID and antiplatelet prescribing were the least complex decision-making of the topics, although all but one GP (who felt NSAIDs had 'no place' in pain control and patients should have no choice in whether to use these drugs) highlighted that it is sometimes complicated by patient's choice.

You know it is a compromise-patients like them [NSAIDs] because they're effective, whatever anybody says without a shadow of doubt people with osteoarthritis find them very effective drugs and often find them far more effective ... for pain relief and symptom relief in total ... than any other medication we've got to give them. (GP Interview 9)

Although the 'antithrombotics in AF' measures led to limited changes in prescribing (3 changes from 201 reviews), two practices perceived the work to be worthwhile and for one it was their most valued prescribing topic, because two patients and the practice were relieved from the burden of unnecessary warfarin therapy. Two practices felt that AF decision-making was often in the hands of consultants, and all GPs reported seeking advice from secondary care regarding the need to initiate or continue warfarin in specific patients. Although GPs reported the notes review work for AF was the most complex, they found validating warfarin prescribing a reassuring process.

the non-steroidal one was great. The atrial fibrillation one was great for a different matter, because [although] you identified quite a lot of patients, at the end of the day, when we looked through them, [we] only identified one that we wanted to chase up. (GP interview 7)

The 'asthma control' topic was perceived as the least important by all GPs, mainly because of overlap with measures in $\mathrm{QOF}^{21}$ and because they shared responsibility with practice nurses and were content to leave the decision-making to them.

I think sometimes we could use the nurses to do some of it...in the future when we do that we would ask our nurse that does the asthma clinic to do that because that would, you know she's the one that's doing the prescribing so that would've been better for her to take control of that. (GP interview 9)

\section{Optimising the intervention}

Practice experiences identified some barriers which facilitated optimising the intervention beyond suggestions in the current literature on changing prescribing.

\section{Facilitating engagement}

GPs felt prescribing safety was important but that improvement was always in the context of busy workloads. A financial incentive to review was perceived as important to facilitate engagement and to encourage practices to participate in the trial. GPs were asked about how any financial incentive should be structured, and different balances between up-front payments and payment-per-review were discussed. Of the options offered, all GPs and practice managers interviewed were 
in agreement that $£ 350$ ( $€ 411$, US\$538) upfront and $£ 15$ $(€ 18, \mathrm{US} \$ 23)$ per review best struck the balance between gaining attention and incentivising payment-per-review.

I think $£ 350$ up front and $£ 15$ per review. The reason for this is that the work is very much about the review and if you pay up-front too much, there is a danger the reviews won't get done as the incentive is small. In fact up-front payment could be less, with more per review, provided you have a mechanism for checking the review has been done properly. (GP Interview 7)

This payment structure mirrors the existing financial incentives for quality in use in the UK general practice, either in the QOF (an explicit pay for performance system) or in enhanced service contracts for work not covered by capitation. ${ }^{22}$

\section{Maintaining engagement}

Two practices struggled to embed the work within practice routines and expressed the concern that DQIP work could be sidelined by competing work pressures. In addition to the pay-per-review financial incentive, it was therefore decided that practices should receive regular updates on their progress (or lack of progress) via DQIP newsletters. It was anticipated that to maintain engagement, unnecessary reviews had to be minimised. This led to a change in how patients were identified so that patients whose high-risk prescribing had been reviewed and deemed appropriate would not be reflagged for review for the same type of high-risk prescribing in the next year.

\section{Sustaining improved prescribing}

All GPs interviewed valued the data but felt high-risk NSAID prescribing required regular review. GPs perceived this was the prescribing topic where prescribing was likely to be restarted because of continuing patient's demand for analgesia and restarting by other doctors.

I think, it will always be very difficult, you will always get colleagues that will go back to prescribing it again and what was interesting was when you were re-running the searches, what was actually happening with that. Looking at what we were doing, because sometimes Dr X would say, 'Crikey look at that! (Practice manager interview 2)

It was decided that the DQIP informatics tool would need to reflag patients for review, where high-risk prescribing was restarted after a decision to stop, and provide run charts to allow practices to monitor highrisk prescribing trends over time.

\section{DISCUSSION}

\section{Summary of main findings}

All topics examined in this study had previously been identified as priorities for improvement in primary care. ${ }^{5}$ GP review of the targeted prescribing revealed that measures for each topic varied in their ability to identify changeable high-risk prescribing and in their perceived importance. The NSAID and antiplatelet measures performed the best in identifying potentially changeable high-risk prescribing $(68 \%$ of patients required action vs $25 \%$ for the 'asthma control' and $18 \%$ of 'antithrombotics in AF') and were the most valued. Although the 'antithrombotics in AF' topic generated considerable work for little change, it was highly valued by two practices because it identified a small number of patients who could stop warfarin, which mattered given the treatment and monitoring burden this drug imposes on patients and practices. The asthma topic was the least valued due to overlaps with QOF reviews and technical problems in accurately identifying patients with poor asthma control from EMRs. These findings demonstrate the importance of testing potential outcome measures prior to trialling complex interventions in order to ensure they are changeable by the intervention to be evaluated. ${ }^{23-25}$ Although practices mentioned improving prescribing safety was important, a number of barriers to engagement, maintenance of effort and sustaining improved prescribing were identified which informed the intervention design ${ }^{24} 26$ and ensured sensitivity to practices' needs. ${ }^{25}$ These barriers were addressed through financial incentives per patient reviewed, and the informatics component would provide continuous measurement and feedback, supplemented by monthly update newsletters.

\section{Strengths and limitations}

A strength of this study was the use of quantitative and qualitative methods to give a broader understanding of how changeable this high-risk prescribing was, what the barriers to changing prescribing were and how GPs valued this work, which enabled informed choice of outcome measures and optimisation of the intervention. ${ }^{24} 2627$ In addition, the findings supported the design of the trial process evaluation ${ }^{28} 29$ along with the main trial design. The main limitation of this study is that changeability of potential outcome measures was tested by measuring GPs' intention to change prescribing or conduct further investigation ('action'), rather than quantifying actual changes in prescribing and their clinical implications. This did, however, allow the identification of plausible high-risk prescribing to use as an outcome measure in the trial which will evaluate the ability of the intervention to actually change prescribing. It is worth noting that although the AF and asthma measures examined were found to be less suitable, this was partly because of technical problems of operationalising them in routine data, and optimising the technical properties of the measures (eg, by extending the time window for warfarin prescriptions in order to reduce the number of patients falsely identified as lacking antithrombotic prophylaxis) may improve their performance. A second limitation of this study was the small number of general practices and reviewing clinicians included, and the four practices involved were of course all 
volunteers, who may not be representative of all practices. This is inevitable in small pilot studies though, and the main trial will evaluate the effectiveness in a wider range of practices with a parallel process evaluation to examine whether and how practices implement the intervention.

\section{Comparison with existing literature}

Although there are many examples of studies developing prescribing measures and establishing their face and content validity, ${ }^{50-33}$ few have reported the extent to which such measures can identify actual opportunities for improvement. ${ }^{3435}$ A Dutch study found that patients identified by a measure-targeting underuse of inhaled corticosteroids in asthma (using prescriptions of shortacting $\beta$ agonists as a proxy for uncontrolled asthma), $46 \%$ were candidates for inhaled steroids after a face-to-face review by a clinician, compared with $25 \%$ at best (assuming all 'further investigations' would confirm the need for inhaled steroids). The much lower proportion found here suggests that estimates of changeability are likely to be context specific (eg, depending on the accuracy of data sources used) and may also depend on the gold standard against which the performance of prescribing measures is compared. When selecting outcome measures for a trial, findings from previous studies conducted in different healthcare settings may therefore be of limited value.

Some of the prescribing measures evaluated here targeted prescribing patterns similar to those used as primary outcome measures in the PINCER trial. ${ }^{11}$ At 6 months of follow-up, the PINCER trial found a significant reduction in $\beta$-blocker prescribing in asthma and NSAID prescribing (without use of gastroprotection in patients with a history of peptic ulcer). ${ }^{36}$ However, part of the improvement in high-risk NSAID prescribing was lost by 12 months of follow-up, which is consistent with concerns expressed by GPs in this study that NSAIDs may be restarted due to patient demand or lack of communication between GPs. The DQIP trial and parallel process evaluations will establish to which extent the strategies used in the DQIP intervention to avoid such relapse (continuous feedback, paying per review and regular letters highlighting progress) is successful.

Our finding that changing prescribing of antithrombotics in $\mathrm{AF}$ is difficult to change is consistent with large surveys conducted over the last 10-15 years, demonstrating little improvement in the uptake of anticoagulants in patients with $\mathrm{AF}$ at high risk of stroke. ${ }^{37-39}$ Similar to our study, a systematic review exploring barriers to prescribing anticoagulants for $\mathrm{AF}$ found that the main reasons not to prescribe anticoagulants were advanced patient's age and perceived risk of bleeding events. ${ }^{40} \mathrm{~A}$ lower uptake of anticoagulants in paroxysmal AF has also previously been reported, consistent with GPs reporting paroxysmal $\mathrm{AF}$ as a reason not to prescribe $\mathrm{AF}$ in this study, although stroke risk is as high as in chronic $\mathrm{AF}^{37}$ This does not mean that such prescribing could not be improved, but may indicate that more attention would need to be paid to persuading GPs of the benefits and risks of antithrombotic use in people with $\mathrm{AF}$, before interventions like this one which prompt review. For the 'Asthma control' topic, some of the interviewed GPs appeared to show complacency (eg, the assumption that if patients have had a QOF asthma review they would be on optimal treatment) and it is possible that where this is the case, then more intensive educational or change facilitating interventions may be required.

\section{CONCLUSION}

Although several studies using the RAND appropriateness method have identified sets of 'valid' indicators, their value and feasibility for change is not usually assessed in terms of the extent to which they identify patients with actual inappropriate prescribing. ${ }^{341}$ This study shows their perceived value and feasibility may vary by prescribing topic, ${ }^{34} 42$ and any research or NHS use of prescribing indicators for improvement would therefore benefit from piloting and evaluation. Some prescribing topics, such as NSAIDs, may be suitable for low-intensity interventions based on repeated feedback using existing electronic data, simple education and possibly small financial incentives but other prescribing topics, such as 'asthma control' and 'antithrombotics in AF' may require prior work to clean electronic data and refine measures, or more intensive educational work to persuade practices what is being measured is important, or more intensive facilitation of change. Safer prescribing is an important aim for policy and commissioners, but there may not be a 'one size fits all' intervention to deliver it.

\section{Author affiliations \\ ${ }^{1}$ Quality, Safety and Informatics Group, Population Health Sciences, Medical Research Institute, University of Dundee, Dundee, UK \\ ${ }^{2}$ Medicines Governance Unit, NHS Tayside c/o University of Dundee, Dundee, UK}

Contributors $B G$ was responsible for the initial conceptualisation and design. TD and AMG reviewed the literature, carried out the data collection, analysis and interpretation of the data and contributed to the design of the study. AMG prepared the first manuscript and is responsible for this article. All authors iteratively commented on successive drafts of the manuscript. All authors read and approved the final manuscript.

Funding During the conduct of the study and preparation of the manuscript, $A G$ and TD were funded by the Scottish Government Health Directorates Chief Scientist Office Applied Programme Research Grant 07/02 for the Data Driven Quality Improvement in Primary Care programme. This funding body have had no direct role in the design and conduct of, or decision to publish this work.

Competing interests AMG and TD are funded by the Scottish Government Health Directorates Chief Scientist Office Applied Programme Research Grant 07/02 for the Data Driven Quality Improvement in Primary Care programme.

Patient consent Obtained.

Ethics approval The study was mixed with qualitative and quantitative methods, and was approved by NHS Tayside Committee on Medical Research Ethics A (09/S1401/54).

Provenance and peer review Not commissioned; externally peer reviewed.

Data sharing statement No additional data are available. 
Open Access This is an Open Access article distributed in accordance with the Creative Commons Attribution Non Commercial (CC BY-NC 3.0) license, which permits others to distribute, remix, adapt, build upon this work noncommercially, and license their derivative works on different terms, provided the original work is properly cited and the use is non-commercial. See: http:// creativecommons.org/licenses/by-nc/3.0/

\section{REFERENCES}

1. Gandhi TK, Weingarten SN, Borus J, et al. Adverse drug events in ambulatory care. N Engl J Med 2003;348:1556-64.

2. Gurwitz JH, Field TS, Harrold LR, et al. Incidence and preventability of adverse events among older persons in the ambulatory setting. J Am Med Assoc 2003;289:1107-16.

3. Pirmohamed MJ, Meakin S, Green C, et al. Adverse drug reactions as a cause of admission to hospital: prospective analysis of 18820 patients. Br Med J 2004;329:15-19.

4. Howard RL, Avery AJ, Slavenburg S, et al. Which drugs cause preventable admissions to hospital? A systematic review. Br J Clin Pharmacol 2007;63:136-47.

5. Dreischulte T, Grant A, McCowan C, et al. Quality and safety of medication use in primary care: consensus validation of a new set of explicit medication assessment criteria and prioritisation of topics for improvement. BMC Clin Pharmacol 2012;12:5.

6. Guthrie B, McCowan C, Davey P, et al. High risk prescribing in primary care patients particularly vulnerable to adverse drug events: cross sectional population database analysis in Scottish general practice. BMJ 2011;342:d3514

7. Howard RL, Avery AJ, Howard PD, et al. Investigation into the reasons for preventable drug related admissions to a medical admissions unit: observational study. Qual Saf Health Care 2003;12:280-5.

8. Thomsen LA, Winterstein AG, Sondergaard B, et al. Systematic review of the incidence and characteristics of preventable adverse drug events in ambulatory care. Ann Pharmacother 2007:41:1411-26.

9. Department of Health. An organisation with a memory: report of an expert group on learning from adverse events in the NHS. 2000

10. Smith J. Building a safer NHS for patients: improving medication safety. London: Department of Health, 2004.

11. Avery AJ, Rodgers S, Cantrill JA, et al. A pharmacist-led information technology intervention for medication errors (PINCER): a multicentre, cluster randomised, controlled trial and cost-effectiveness analysis. Lancet 2012;379:1310-19.

12. Dreischulte $\mathrm{T}$, Grant $\mathrm{A}$, Donnan $\mathrm{P}$, et al. A cluster randomised stepped wedge trial to evaluate the effectiveness of a multifaceted information technology-based intervention in reducing high-risk prescribing of non-steroidal anti-inflammatory drugs and antiplatelets in primary care: the DQIP study protocol. Implement Sci 2012;7:24.

13. Medical Research Council. A framework for the development and evaluation of RCTs for complex interventions to improve health. London: Medical Research Council, 2000.

14. Campbell M, Fitzpatrick R, Haines A, et al. Framework for design and evaluation of complex interventions to improve health. BMJ 2000;321:694-6.

15. O'Brien MA, Rogers S, Jamtvedt G, et al. Educational outreach visits: effects on professional practice and health care outcomes. Cochrane Database Syst Rev 2009;4:CD000409.

16. Farmer AP, Legare F, Turcot $L$, et al. Printed educational materials: effects on professional practice and health care outcomes. Cochrane Database Syst Revi 2008;(3):CD004398.

17. Jamtvedt G, Young JM, Kristoffersen DT, et al. Audit and feedback: effects on professional practice and health care outcomes. Cochrane Database Syst Rev 2009;(4).

18. Gage BF, Waterman AD, Shannon W, et al. Validation of a clinical classification schemes for predicting stroke: results from the National Registry of Atrial Fibrillation. J Am Med Assoc 2001;285:2864-70.

19. Ritchie J, Spencer L, O'Connor W. Carrying out qualitative analysis. In: Ritchie J, Lewis J. eds Qualitative research practice, a guide for social science students and researchers. London: Sage, 2003.

20. Camm AJ KP, Lip GYH, Schotten U, et al. Guidelines for the management of atrial fibrillation. Eurospace 2010;12:1360-420.
21. Department of Health. Investing in General Practice-the New General Medical Services Contract. 2003.

22. British Medical Association. Focus on QOF payments. http://bma. org.uk/practical-support-at-work/contracts/independent-contractors/ qof-guidance/focus-qof-payments (accessed 25 Nov 2013)

23. Campbell S, Chauhan U, Lester $\mathrm{H}$. Primary Medical Care Provider Accreditation (PMCPA): pilot evaluation. Br J Gen Pract 2010; e295-301.

24. Bradley F, Wiles R, Kinmonth A-L, et al. Development and evaluation of complex interventions in health services research: case study of the Southampton heart integrated care project (SHIP). BMJ 1999;318:711-15.

25. Van Hecke A, Verhaeghe S, Grypdonck M, et al. Systematic development and validation of a nursing intervention: the case of lifestyle adherence promotion in patients with leg ulcers. $J$ Adv Nurs 2011;67:662-76.

26. Corrrigan M, Cupples ME, Smith SM, et al. The contribution of qualitative research in designing a complex intervention for secondary prevention of coronary heart disease in two different healthcare systems. BMC Health Serv Res 2006;6:90.

27. Cresswell K, Sadler S, Rodgers S, et al. An embedded longitudinal multi-faceted qualitative evaluation of a complex cluster randomized controlled trial aiming to reduce clinically important errors in medicines management in general practice. Trials 2012;13:78.

28. Grant A, Dreischulte T, Treweek S, et al. Study protocol of a mixed-methods evaluation of a cluster randomised trial to improve the safety of NSAID and antiplatelet prescribing: data-driven quality improvement in primary care. Trials 2012;13:154.

29. Grant A, Treweek S, Dreischulte T, et al. Process evaluations for cluster-randomised trials of complex interventions: a proposed framework for design and reporting. Trials 2013;14:15.

30. Gallagher P, Ryan C, Byrne S, et al. STOPP (Screening Tool of Older Person's Prescriptions) and START (Screening Tool to Alert doctors to Right Treatment). Consensus validation. Int J Clin Pharmacol Ther 2008;46:72-83.

31. Naugler CT, Brymer C, Stolee P, et al. Development and validation of an improving prescribing in the elderly tool. Can J Clin Pharmacol 2000;7:103-7.

32. Fick DM, Copper JW, Wade WE, et al. Updating the Beers criteria for potentially inappropraite medication use in older adults, resulting of a US consenus panel of experts. Arch Intern Med 2003;163:2716-24.

33. Avery A, Dex G, Mulvaney C, et al. Development of prescribing-safety indicators for GPs using the RAND appropriateness method. Br J Gen Pract 2011;61:e526-36.

34. Pont LG, Denig P, van der Molen T. Validity of performance indicators for assessing prescribing quality: the case of asthma. Eur J Clin Pharmacol 2004;59:833-40.

35. Dreischulte T, Johnson J, McAnaw J, et al. Medication assessment tool to detect care issues from routine data: a pilot study in primary care. Int J Clin Pharm 2013;35:1063-74.

36. Hemming K, Chilton PJ, Lilford RJ, et al. Bayesian cohort and cross-sectional analyses of the PINCER trial: a pharmacist-led intervention to reduce medication errors in primary care. PLOS ONE 2012; 7:e38306.

37. Nieuwlaat R, Capucci A, Lip GY, et al. Antithrombotic treatment in real-life atrial fibrillation patients: a report from the Euro Heart Survey on Atrial Fibrillation. Eur Heart J 2006;27:3018-26.

38. Holt TA, Hunter TD, Gunnarsson C, et al. Risk of stroke and oral anticoagulant use in atrial fibrillation: a cross-sectional survey. $\mathrm{Br} \mathrm{J}$ Gen Pract 2012; 62: e710-17.

39. Ogilvie IM, Newton N, Welner S. Underuse of oral anticoagulants in atrial fibrillation: a systematic review. Am J Med 2010;123:638-45.

40. Pugh D, Pugh J, Mead GE. Attitudes of physicians regarding anticoagulation for atrial fibrillation: a systematic review. Age Ageing 2011:40:675-83.

41. Campbell SM, Cantrill JA, Roberts D. Prescribing indicators for UK general practice: Delphi consultation study. BMJ 2000;321:425-8.

42. Campbell S, Hann M, Hacker J, et al. Quality assessment for three common conditions in primary care: validity and reliability of review criteria developed by expert panels for angina, asthma and type 2 diabetes. Qual Saf Health Care 2002;11:125-30. 